\title{
Deliberate long-term exceeding of recommended dose of venlafaxine by a dysthymic patient. a case report Emmanuil Patelaros
}

\author{
Address: Mental Health Center, Kavala, Greece \\ from International Society on Brain and Behaviour: 3rd International Congress on Brain and Behaviour \\ Thessaloniki, Greece. 28 November - 2 December 2007 \\ Published: 17 April 2008 \\ Annals of General Psychiatry 2008, 7(SuppI I):SI 23 doi:I0.II86/I744-859X-7-SI-SI 23
}

This abstract is available from: http://www.annals-general-psychiatry.com/content/7/SI/SI 23

(C) 2008 Patelaros; licensee BioMed Central Ltd.

\section{Background}

Prescription of drugs must follow established guidelines, especially concerning maximum daily dose. Nevertheless some clinicians and researchers often try high doses for optimizing results. Patients also tend to raise the doses especially of anxiolytics and analgetics

\section{Materials and methods}

We present a case report of a dysthymic patient who, by his own decision and against the doctor's recommendations, continuously receives venlafaxine at a dose almost double than the officially maximum recommended

\section{Results}

A 38 year old man who suffered of dysthymia following a head injury after a car crash, presented for treatment. He had no permanent neurological and cognitive consequences except from dizziness. Treatment started with venlafaxine, as another agent tried before proved inefficient. Following titration the psychiatrist recommended the dose of $300 \mathrm{mgs}$ per day by means of XR capsules. The recommended maximum daily dose of the certain drug is $325 \mathrm{mgs}$. At the following visits his condition had improved but with no complete remission. During the regular once-per-month follow-up the patient announced that he had by his own decision increased the dose to $600 \mathrm{mg}$ daily, and he felt much better. Despite the continuous precautions given by the doctor about the maximum dose and the possible harm he insisted to his initial decision managing to obtain the extra amount by means of private purchasing. The tests he underwent for liver and renal function were normal, and the ECG showed moderate elevation of heart rate. He suffers minor side-effects like constipation and dry mouth. He continues to do so for 2 years now.

\section{Conclusions}

The above case report is presented for discussion in two topics. A. the limits of dose-related response of venlafaxine, and $\mathrm{B}$. the possible altered pharmacokinetics of venlafaxine in certain patients.

\section{References}

I. Langford NJ, Martin U, Ruprah M, Ferner RE: Alternative venlafaxine kinetics in overdose. J Clin Pharm Ther 2002, 27(6):465-7. Dec 